\title{
A Parametric Study of Jointed Plain Concrete Pavement Using Finite Element Modeling
}

\author{
Monireh Zokaei ${ }^{1}$, Mansour Fakhri ${ }^{1} \&$ Saeed Rahiminezhad ${ }^{2}$ \\ ${ }^{1}$ Department of Civil Engineering, KN Toosi University of Technology, Tehran, Iran \\ ${ }^{2}$ Department of Civil Engineering, Islamic Azad University, Tehran, Iran \\ Correspondence: Mansour Fakhri, Department of Civil Engineering, KN Toosi University of Technology, Tehran, \\ Iran. Tel: 98-9121-402-964. E-mail: fakhri@kntu.ac.ir
}

$\begin{array}{ll}\text { Received: September 26, } 2017 & \text { Accepted: October 4, } 2017 \quad \text { Online Published: October 31, } 2017 \\ \text { doi:10.5539/mas.v11n11p75 } & \text { URL: https://doi.org/10.5539/mas.v11n11p75 }\end{array}$

The research is financed by Kntu University.

\begin{abstract}
Concrete pavements face various types of distresses such as longitudinal, transverse, and joint cracking due to traffic loading and thermal stresses. The objective of this investigation was to develop Three-Dimensional Finite-Element Models (3D-FEM) to assess the performance of dowel in Jointed Plain Concrete Pavement (JPCP).

Finite-element modeling is a powerful tool that can be used for the simulation of the structural response of pavements under the effects of different loading condition. Most of the previous studies ignored important factors, including the combined effect of dynamic axle loads and thermal gradient. Overcoming the shortcomings of the previous studies, this study investigated the pavement response under the effect of some model parameters. The result of the study was verified by a comparison with field measurements. Results also showed that the combined negative gradient and axle loads located at the transverse joint subject the top of mid-slab, to high tensile stress that may explain the initiation of top-down cracks. These stresses increase under corner loading when the slab length is increased. In general, the study presented that the developed 3D-FEM is suitable for identifying the effect of different design features including pavement geometry, material properties, thermal gradients, and axle load and configuration on the structural response of rigid pavements.
\end{abstract}

Keywords: jointed concrete pavement, finite element modeling, thermal gradient, dowel bar, ABAQUS

\section{Introduction}

The first model of a rigid pavement as a slab-on-grade system was presented by Westergaard in the 1920's. He developed his method to calculate stresses and deflections in rigid pavements due to interior, edge and corner loads later (Westergaard, 1927). The poor assumption concerning the modeling of thin slab layer and foundation and the, thermal loads, and modeling load transfer devices were the main weaknesses of the Westergaard method (Wang, Sargious \& Cheung, 1972).

A substantial amount of research and developments have been conducted for years to provide an analytical tool that would be able to model and analyze the behavior of rigid pavements. Several analytical softwares for modeling jointed concrete slabs on top of elastic foundations have been developed in the last five decades. The development of a 3D-FEM comprises a major part of the new design methods (Brill, Hayhoe \& Lee, 1997).

Nonlinear thermal gradient yield stresses in slabs owing to their external and internal restraints, including subgrade reaction, edge contact between adjacent slabs and slab-foundation friction as the external restraints due to thermal curling and thermal expansion or contraction. The restraining interaction of surrounding layers across the slab depth, which resists against the distortion of the slab as a consequence of the nonlinear thermal gradient, can produce additional internal stresses in the slab (Zokaei-Ashtiani et al. 2013; Ioannides, Peng, \& Swindler, 2006).

There are three types of joints used in concrete pavements: contraction joints, construction joints and expansion joints. Load transfers are in both the longitudinal and transverse joints to handle the applied load by traffic and 
environment, from one slab to the adjacent slab (Byrum \& Ye, 2012). Shorter slab lengths need a larger number of joints and therefore, higher construction costs.

The FE method is a method for solving problems with complex geometries, loading, and material properties numerically. Cheung and Zienkiewicz analyzed the rigid pavement using the finite element for both semi-infinite elastic continuum and Winkler foundation for the first time (Cheung \& Zinkiewicz, 1965). Numerous software introduced for rigid pavement analysis afterward by various researchers (Chou, 1981; Huang \& Wang, 1973; Tabatabaie, Barenberg \& Smith, 1979; sHoerner et al. 2000; Ioannides et al. 1984). The 2D finite-element modeling had several limitations, they were unable to model more than two layers above the subgrade, and only one slab laying on top of a Winkler during temperature analysis could be considered. The 2D models were unable to model dynamic loading and many incapabilities where can be found in the literature (Davids, Turkiyyah \& Mahoney, 1998). With increasing computers speed and power, 3D modeling was adopted by many researchers, which had significant improvement over traditional design methods, including the availability of interface algorithms and thermal modules.

Since 70's various softwares were developed to deal with the analyzing pavements, including DYNA-3d, NIKE3D, LS-DYNA and etc (Shoukry, William \& Srinivasan, 2002; Shoukry, William \& Riad, 2003). ABAQUS software was also used to simulate concrete pavement in many researches (Ioannides, Peng, \& Swindler, 2006; Hesami \& Sadeghi, 2015). Darter et al. examined loss support under the effect of static loads (Darter, Hall \& Kuo, 1995). Zaghloul investigated the effects of increasing load speed from 2.8 to $16 \mathrm{~km} / \mathrm{hr}$. using ABAQUS (Zaghloul et al. 1994). Zaman et al. used ABAQUS to analyze the dynamic response of airport pavement subjected to temperature gradient and wheel loading. He showed that increasing the temperature gradient of the slab increases both the tensile stress and the deflection of the pavement.

The previous studies had some shortcomings, including neglecting modeling dowel bars with proper elements. Often beam or spring elements were used in the modeling process. The load transfer across the joints were also simulated by either shear elements or frictional behavior. The study of the combined effect of the moving load and nonlinear temperature gradient was also neglected. The objective of this study is to propose a new model to overcome the shortcoming of the previous researches.

\section{Model Description}

Finite-element modeling of concrete pavements should include detailed 3D modeling of dowel bars and its interfaces with the surrounding concrete in addition to the standard capability of handling thermal effects. This implies that the finite-element mesh should be fine, a requirement that increases the processing time but ensures the accuracy for the results. A two- slab system with a 10-mm joint width above supporting layers was modeled using ABAQUS program.

Solid 3D deformable element (C3D8R) was used to model the concrete pavement. The model geometry is similar to the model introduced by Shoukry et al. (2002). The $254 \mathrm{~mm}$ thick slabs were $4600 \mathrm{~mm}$ long and 3660 $\mathrm{mm}$ wide, with a modulus of elasticity, $\mathrm{E}=30000 \mathrm{MPa}$, a Poisson's ratio, $V_{\text {of }} 0.18$ and a density of $2400 \mathrm{~kg} / \mathrm{m} 3$. Base had a $200 \mathrm{~mm}$ thickness $(\mathrm{E}=350 \mathrm{MPa}$ and $V=0.3$ ) modelled on top of the subgrade with $\mathrm{E}=30 \mathrm{MPa}$ and $v$. A bonded interface was considered between subgrade and base. Sliding interfaces with frictional contact were selected between the concrete and the subgrade $(\mu=1.5)$ and between each dowel and the surrounding concrete $(\mu=0.05)$. The wheel loads were applied on contact patches moving on the slab at a speed of $105 \mathrm{~km} / \mathrm{hr}$ based upon the literature a 16.3-tons load was preferred in this study for the tandem axle (Siddharthan, Sebaaly $\&$ Zafir, 1996). A non-reflective boundary is considered at the bottom of the model, as shown in Fig. 1. A refined mesh zone was selected for the center of the joint, where wheel loads are applied. Fig. 2 and Fig. 3 show the finite- element mesh used for the study. 


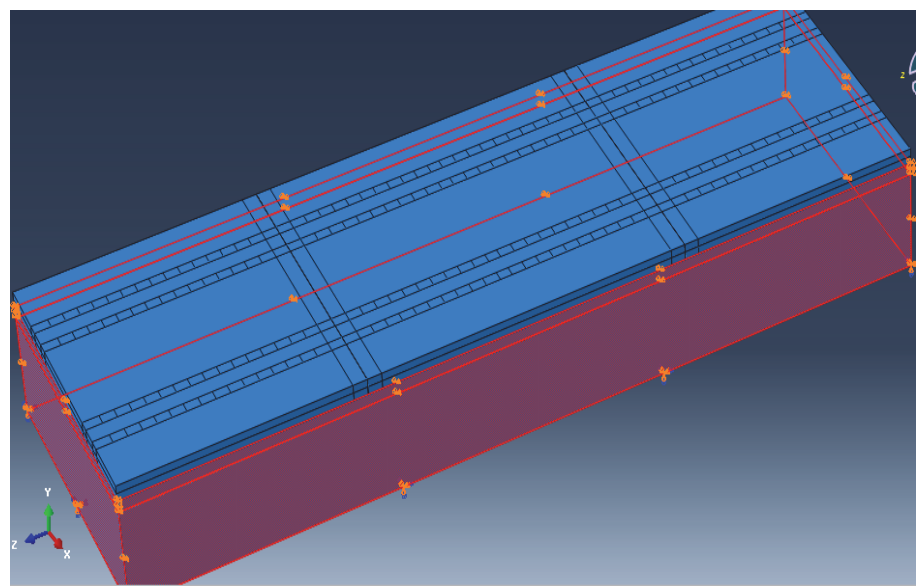

Figure 1. The boundary condition

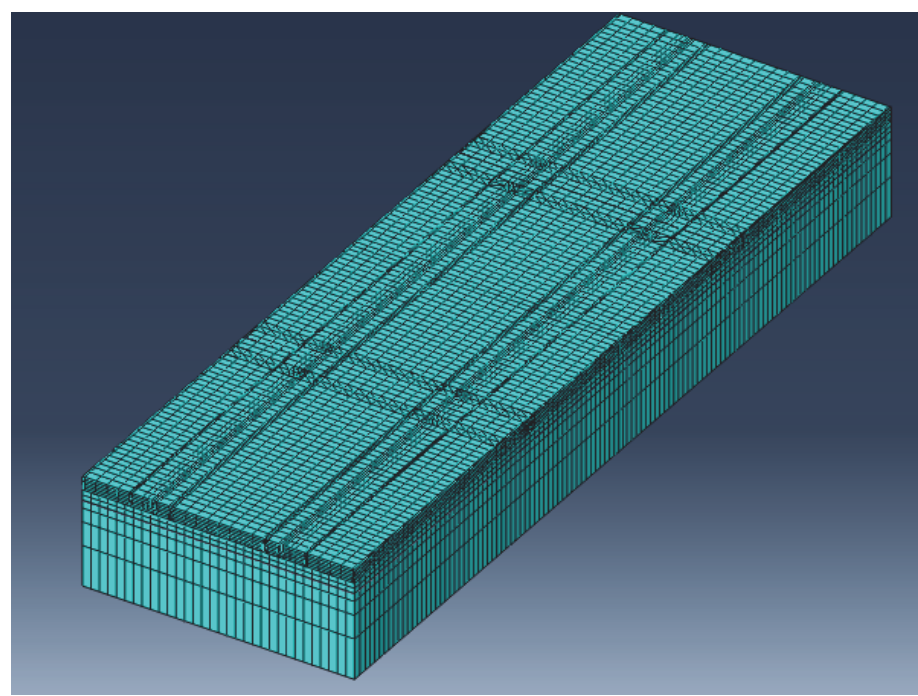

Figure 2. Finite element mesh used in the study

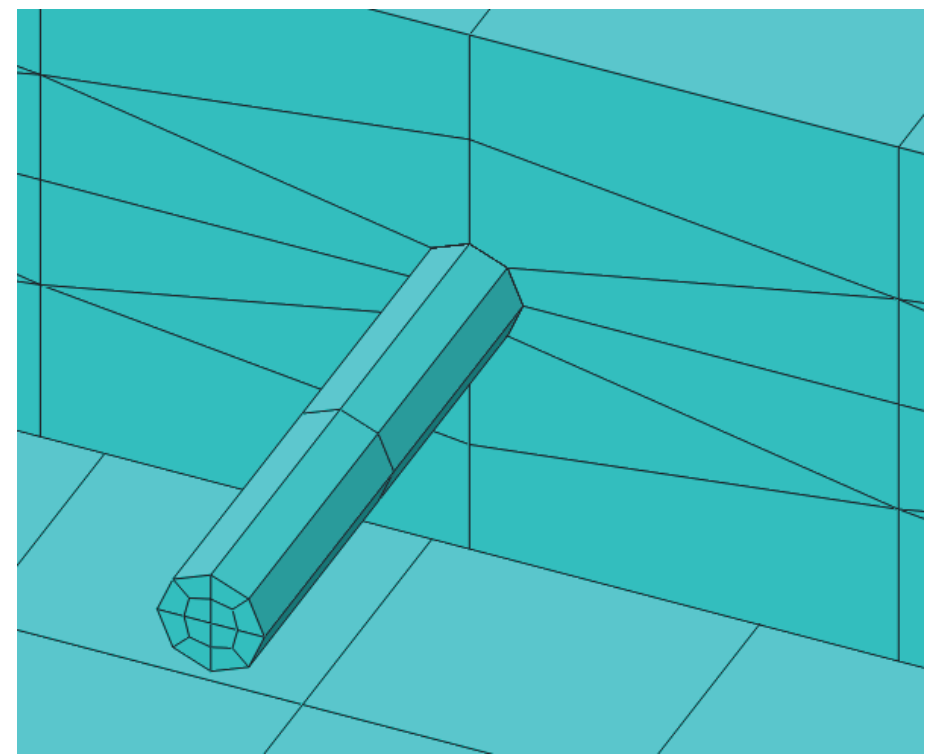

Figure 3. Finite element mesh around the dowel bar

In this study, the history of a certain parameter, versus the distance of the front axle from a certain point will be 
plotted against the parameter history. The negative sign of the distance means that the moving load is moving toward the element, and a positive distance means that the load is moving away from it. The histories developed in four elements, which fall along the inner wheel-path are examined. Fig. 4 shows a schematic of the four elements selected. Two of which are located at the slab top and bottom at mid slab length, called elements M1 and M2. The other two elements are located at the slab top and bottom at the edge of the second transverse joint, elements $\mathrm{J} 1$ and $\mathrm{J} 2$. These locations were selected to compare the output of the FEM with the existing field results which are described later.

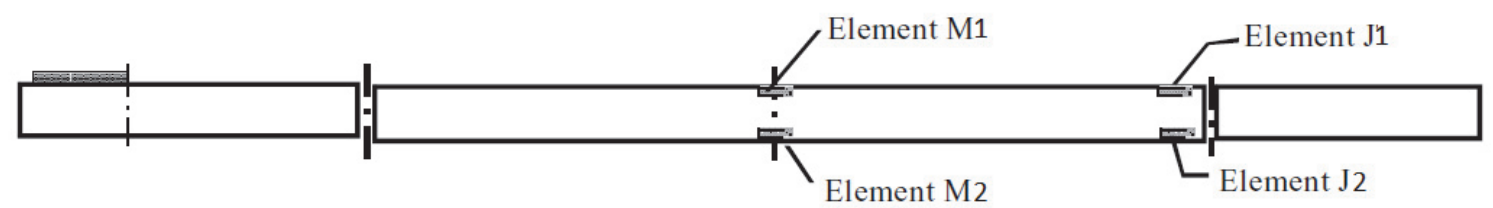

Figure 4. location of the elements studied (William \& Shoukry, 2001)

The model is verified with the results of the Ohio road test results (Shoukry, Martinelli \& Reigle, 1997). The locations of the sensors in the road test is shown in Fig. 5.

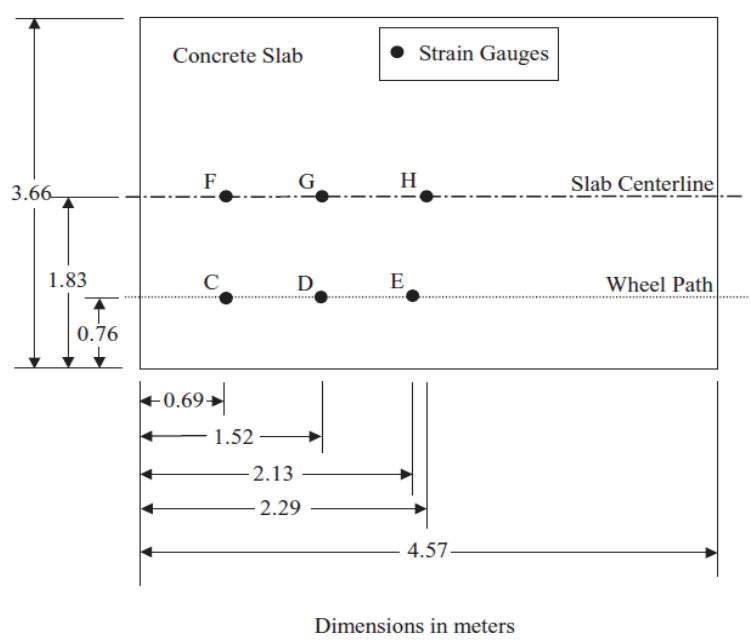

Figure 5. Location of the sensor in the road test (Sargand \& Breegle, 1998)

The longitudinal strains from the finite element are compared to results of the road test and shown in Fig. 6. The result shows that the FEM model used in this study is accurate and can be used to simulate concrete pavements.
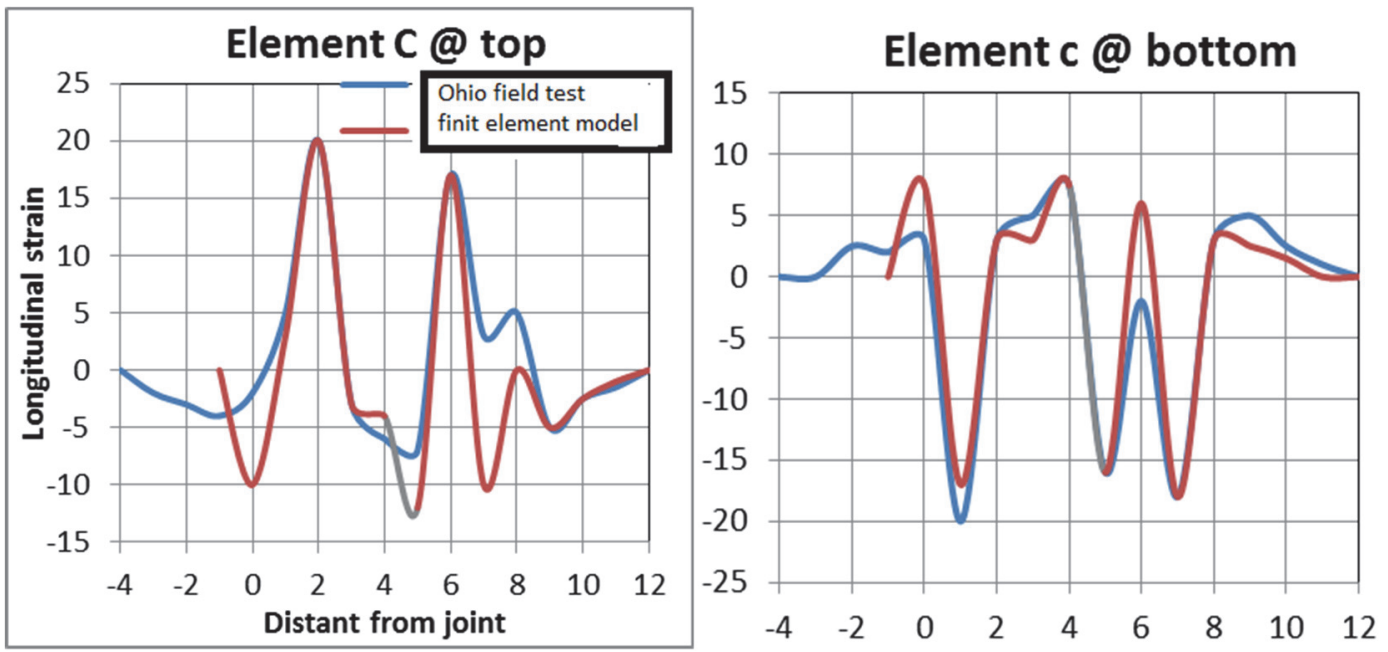

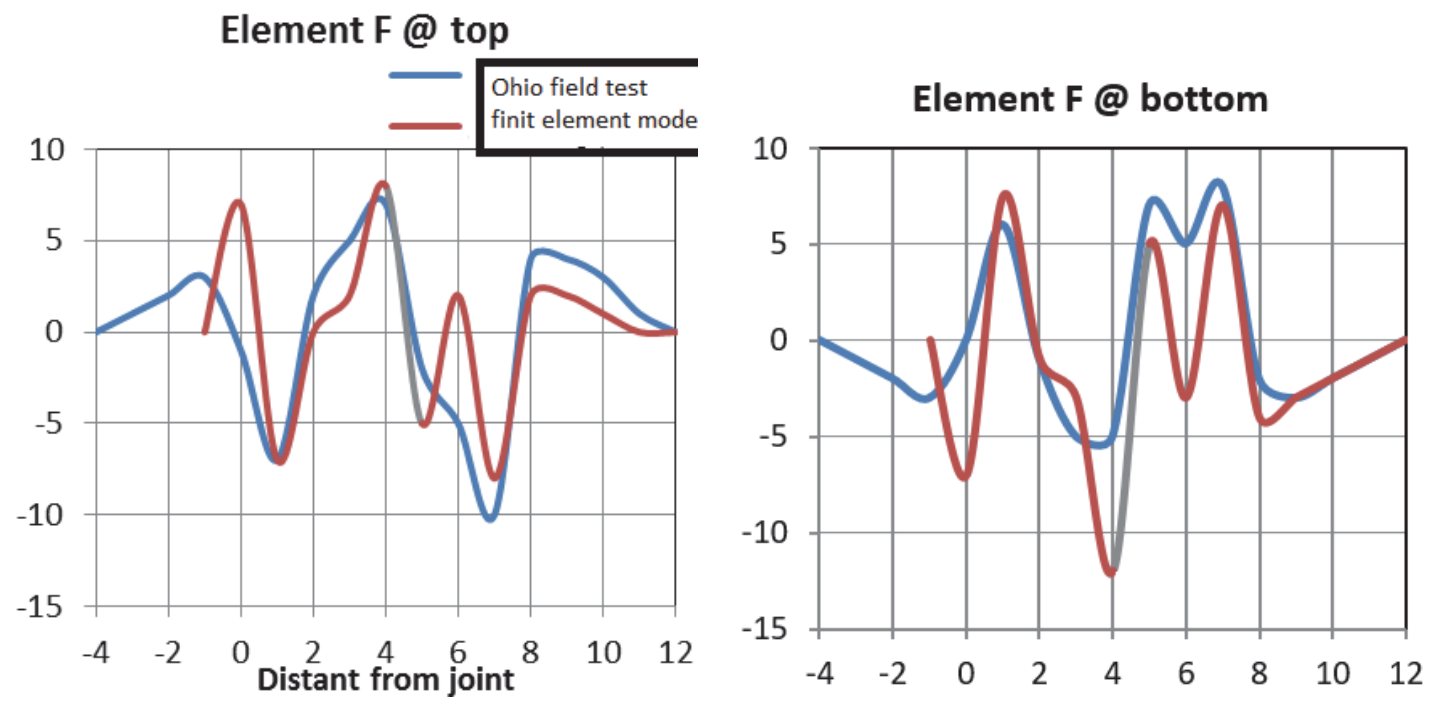

Figure 6. Verification of the FEM model with the results of the OHIO test

\section{Results}

Fig. 7 shows the deformed shape of the slab from the results of the FE analysis. Tensile stresses can lead to the cracking progress alongside the pavement centerline. Observed tensile stresses at the bottom of the slab are higher than the top. Longitudinal cracking might initiate from both top and bottom of the slab. The highest peak of tensile stress experienced when an axle load is passed the joint, but the second axle is yet on the latter slab.

Fig. 8 shows unconstrained and side constrained boundary condition along the lateral slab edge simulating a road with/without shoulder. $\varepsilon_{z}$ is plotted for the elements introduced previously. It is shown that strain is not influenced by constraining lateral side.

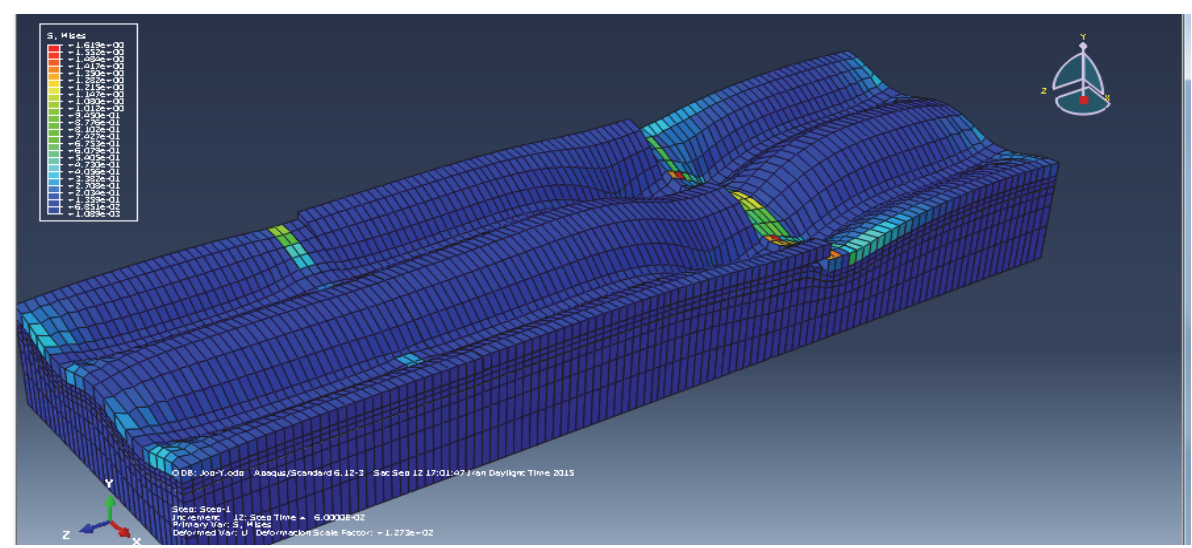

Figure 7. Deformation of the pavement

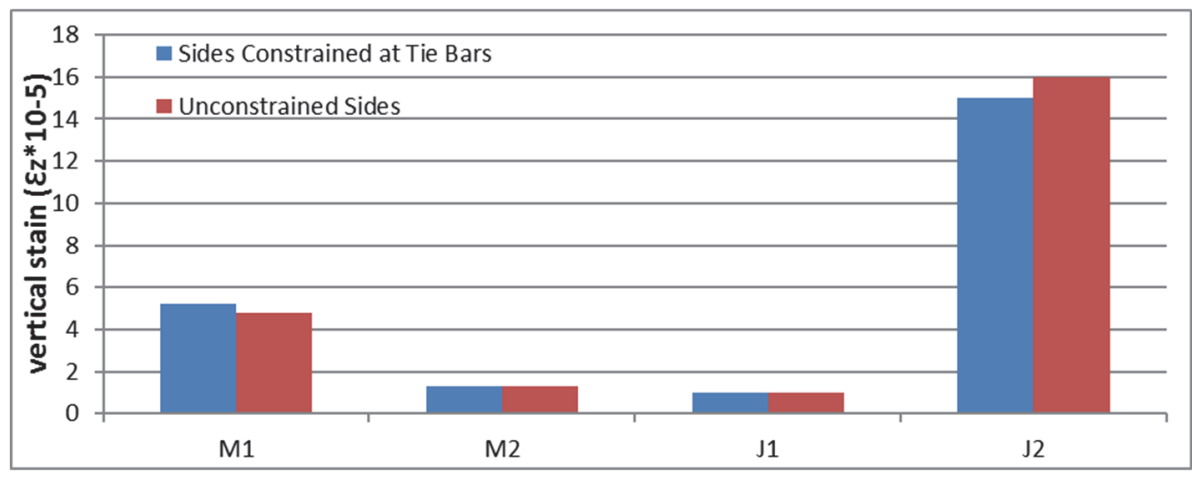

Figure 8. Effects of tie bars on the vertical strains 
Fig. 9 shows the effects of the interface between concrete and base on the maximum principal stress at the bottom of the pavement. Bonding the two layers causes an extra tensile stress and strain at the slab bottom which increases when the first axle is on the approach slab, and the second axle load left the slab edge. Transverse joints are more susceptible to concrete/base bond.

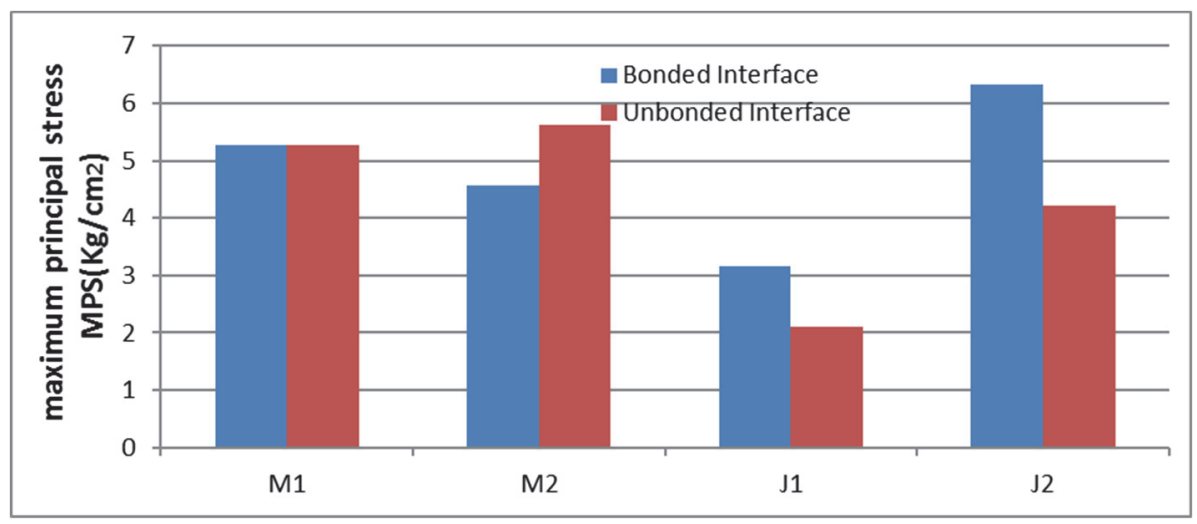

Figure 9. Effects of the interface of the slab/base on the maximum principal stress within slab

Fig. 10 and Fig. 11 show the effects of joint opening on the maximum principal stress and maximum longitudinal stress within the pavement. Two cases were studied, first with a $19 \mathrm{~mm}$ joint width and without joint where the aggregate interlock exists for transferring load to the adjacent slab.

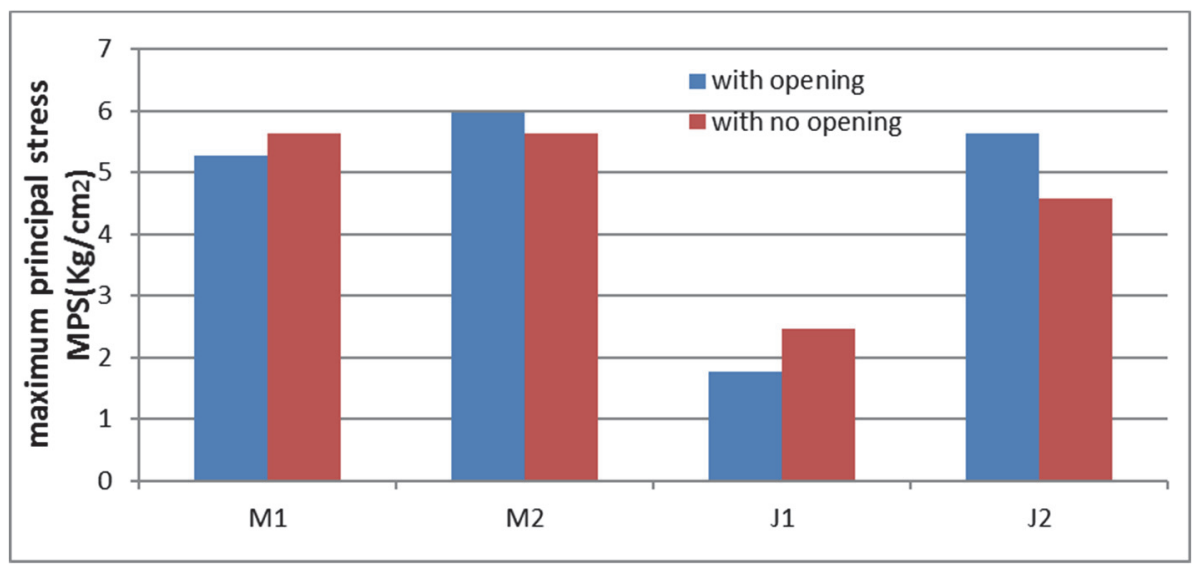

Figure 10. The effects of joint opening on the maximum principal stress induce

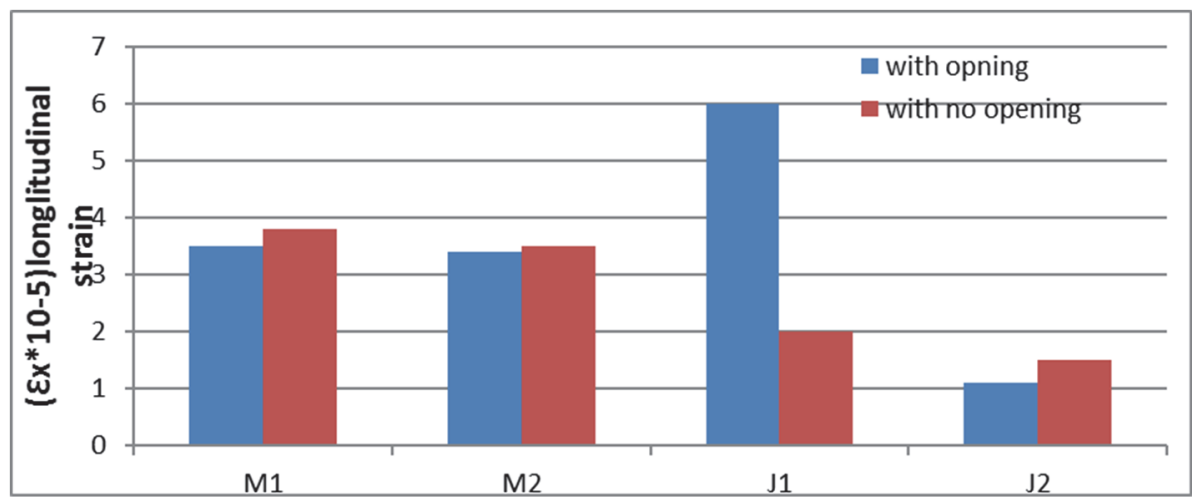

Figure 11. The effects of joint opening on the maximum longitudinal strain

The maximum principal stress and longitudinal strain are plotted for each element. The results showed that aggregate interlock increases $\varepsilon x$ induced at the bottom of the slab along the transverse joint. The pictures revealed that the joint width is only effective on the stress and strain induced at the joints and does not have 
effects on the mid slab.

The effect of the slab length on the response of the pavement is shown in Fig. 12. It is shown that reducing slab length to $3.1 \mathrm{~m}$ didn't have much effect on the maximum principal stress and deflection at mid slab or joints. Generally, the change in slab length is not effective on pavement response at mid slab. In case of the thermal gradients, the result may be different.

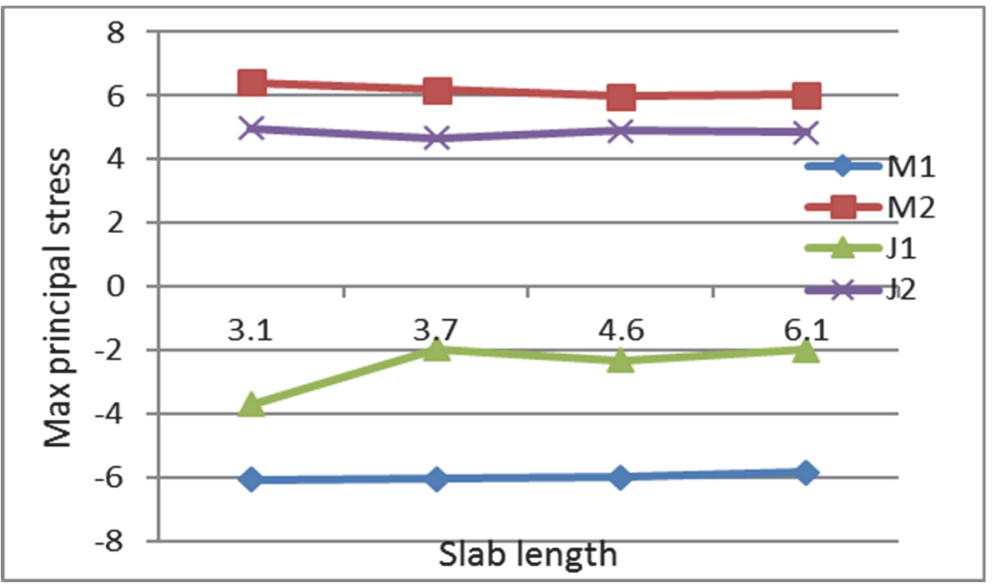

Figure 12. Effect of the slab length on the maximum principal stress induced in concrete slab

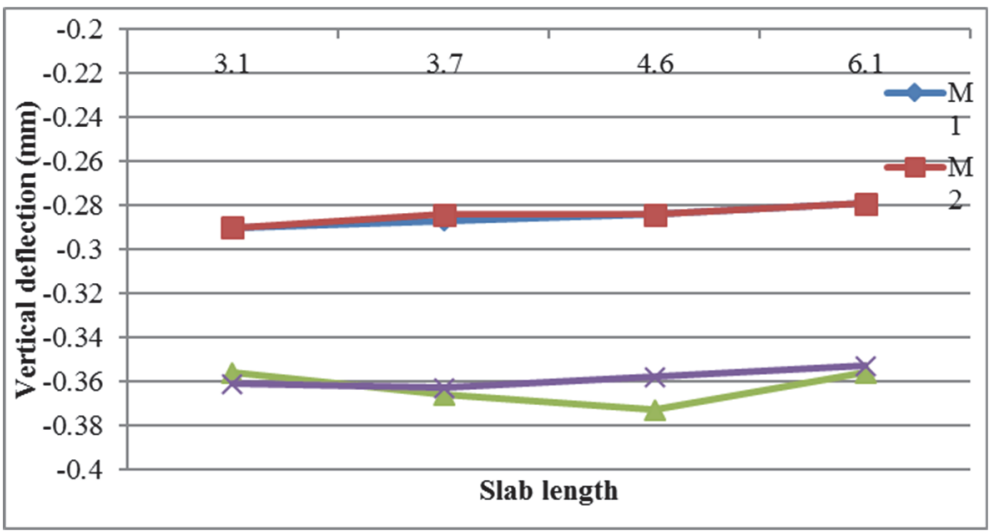

Figure 13. Effect of slab length on the maximum vertical deflection

The selection of slab thickness is related to structural and economic issues. In this study, the effect of increasing slab thickness is investigated. The 11 percent increase in the slab thickness reduced maximum principal stress and longitudinal strain within the pavement. The reduction in the joints is more than that at the mid slab as it is shown in Fig. 14 and Fig. 15.

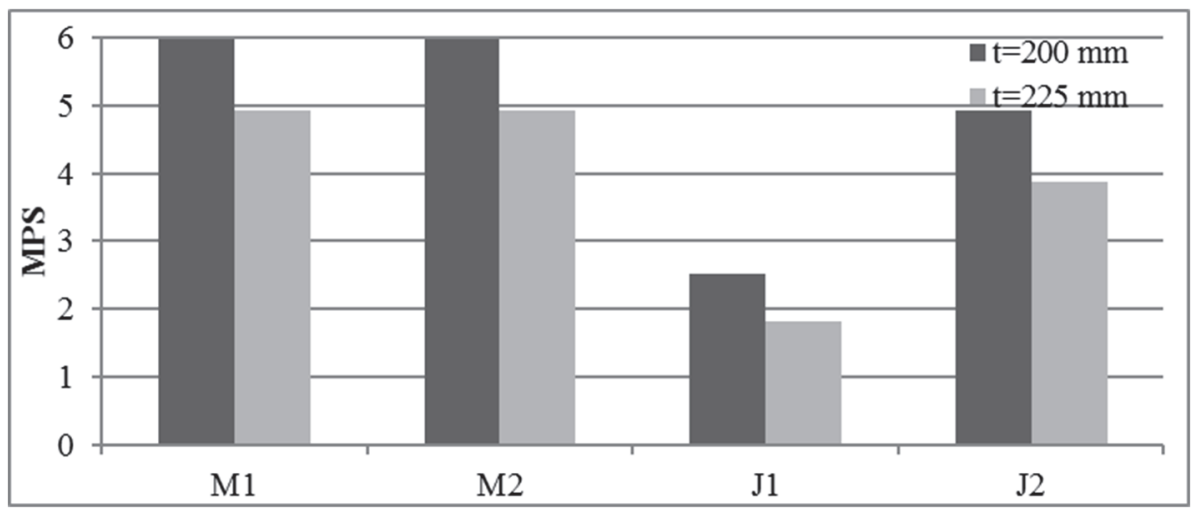

Figure 14. The effects of slab thickness on the maximum principal stress 


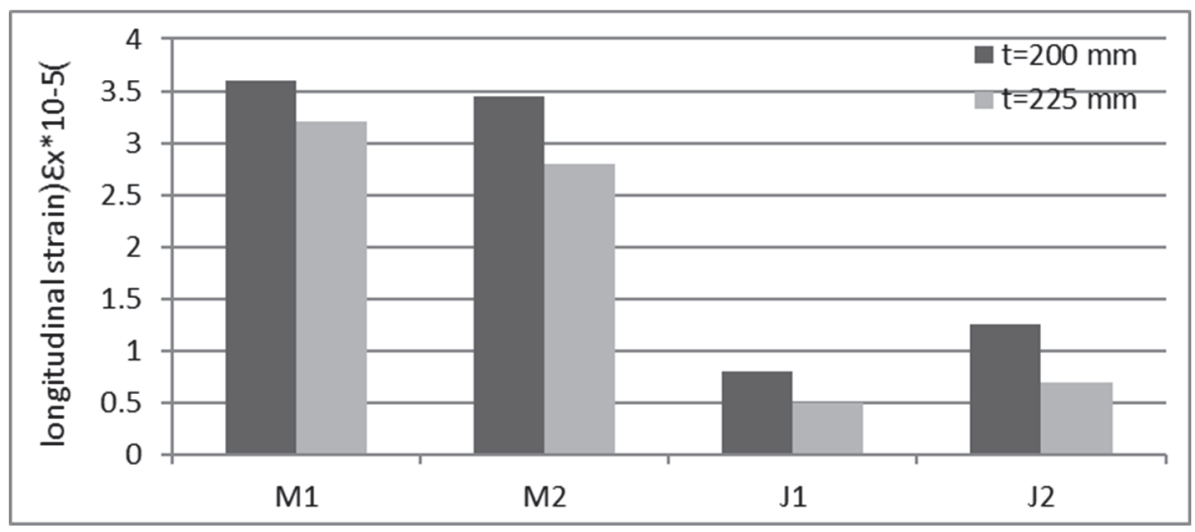

Figure 15. The effects of the slab thickness on the maximum longitudinal strain

Thermal gradient causes slab to curl and the corners separate from the beneath layer. In this study, three types of the loading are applied in finite-element modeling. Thermal gradient, slab weight and axle loads. All layers are modeled using linear elastic materials. The nonlinear gradient profiles that used in the study were presented by Shoukry et al. (2000) are as follows:

1. Negative thermal gradient of $-5^{\circ} \mathrm{C}$ measured at midnight given by:

$$
\text { Tneg9 }=0.0121 \mathrm{z}^{3}-0.237 \mathrm{z}^{2}-2.1394 \mathrm{z}^{-6}
$$

2. Negative thermal gradient of $-6.7^{\circ} \mathrm{C}$ measured at $5: 30$ am given by:

$$
\text { Tneg } 12=0.0022 z^{3}-0.029 z^{2}-1.767 z-7.15
$$

3. Negative thermal gradient of $-14.45^{\circ} \mathrm{C}\left(-26^{\circ} \mathrm{F}\right)$ given by:

$$
\text { Tneg26=-0.0107(z+9) } 3)^{3}-0.3321(z+9)^{2}-4.9903(z+9)+16.9167
$$

4. Positive thermal gradient of $+7.14^{\circ} \mathrm{C}\left(+13^{\circ} \mathrm{F}\right)$ measured at $10: 30 \mathrm{am}$. given by:

$$
\text { Tpos13 }=-0.01(\mathrm{z})^{3}+0.1246 \mathrm{z}^{2}+3.3608 \mathrm{z}+11.662
$$

5. Positive thermal gradient of $+10^{\circ} \mathrm{C}\left(+18^{\circ} \mathrm{F}\right)$ measured at $12 \mathrm{am}$. given by:

$$
\text { Tpos } 18=0.0214(z) 3+0.4806 z 2-4.6443 z+12.7058
$$

6. Positive thermal gradient of $+14.45^{\circ} \mathrm{C}\left(+26^{\circ} \mathrm{F}\right)$ measured at $4 \mathrm{pm}$. given by:

$$
\text { Tpos } 26=0.0107(z) 3+0.3321 z 2-4.9903 z+16.9167
$$

$\mathrm{z}$ is the depth of the point at which temperature changes from the slab top. The axle loads move at a speed of 105 $\mathrm{km} / \mathrm{hr}$.

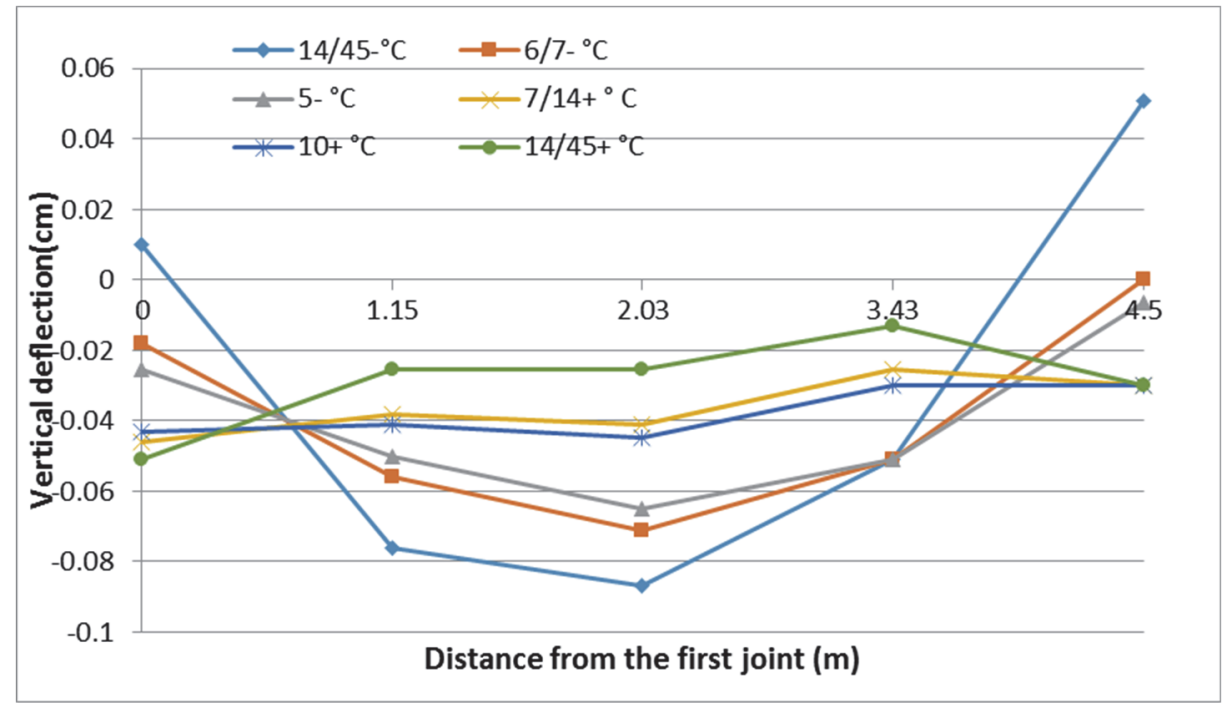

Figure 16. The effect of thermal gradient on the vertical deflection 
Fig. 16 shows the vertical deflection at the bottom of the slab for the negative gradients of $5,6.2$ and $14.45^{\circ} \mathrm{C}$ and positive gradients of $7.14,10$ and $14.45^{\circ} \mathrm{C}$. the deflection is plotted against the distance from the transverse joint. Results show a significant change in the slab curl due to change in the gradient. The curl is also influenced by axle load. The negative gradient is more dangerous at nights due to heavier traffic.

\section{Conclusion}

In this study a 3D finite element was presented to assess the combined and separated effects of the moving axel load and thermal gradient. The model was verified with the result of Ohio road test. The results of the parametric study showed that:

- The change in the slab length is not effective on the pavement response

- Increasing slab thickness reduced stress and strains induced at concrete slabs. The stress reduction is more evident at the joints.

- Aggregate interlock increased horizontal strain at bottom of the slab at transverse joints.

- Increasing slab thickness reduced maximum principal stress and horizontal strain which is more noticeable at mid slab.

- The slab curve changes significantly with the change of thermal gradient from the positive to negative.

\section{References}

Brill, D. R., Hayhoe, G. F., \& Lee, X. (1997). Three-dimensional finite element modeling of rigid pavement structures. in Aircraft/Pavement Technology in the Midst of Change.

Byrum, C. R., \& Ye, D. (2012). Evaluating the effect of concrete slab curling on joint load transfer responses. Journal of the Transportation Research Board, 2305(1), 43-53.

Cheung, Y., \& Zinkiewicz, O. (1965). Plates and tanks on elastic foundations - an application of finite element method. International Journal of Solids and structures, 1(4), 451-461.

Chou, Y. T. (1981). Structural Analysis Computer Programs for Rigid Multicomponent Pavement Structures with Discontinuities--WESLIQID and WESLAYER. Report 1. Program Development and Numerical Presentations. 1981, DTIC Document.

Darter, M. I., Hall, K.T., \& Kuo, C. M. (1995). Support under Portland cement concrete pavements.

Davids, W. G., Turkiyyah, G. M., \& Mahoney, J. P. (1998). Modeling of Rigid Pavements: Joint Shear Transfer Mechanisms and Finite Element Solutions Strategies.

Hesami, S., \& Sadeghi, V. (2015). Numerical Investigation of the Shape Memory Alloy Dowels in Jointed Concrete Pavements. International Journal of Pavement Research and Technology, 8(4), 251.

Hoerner, T., et al. (2000). Improved Prediction Models for PCC Pavement Performance-Related Specifications, Volume I: Final Report.

Huang, Y., \& Wang, S. (1973). Finite-element analysis of concrete slabs and its implications for rigid pavement design. Highway Research Record, 1973(466).

Ioannides, A. M., et al., (1984). Analysis of Slabs-on-Grade for a Variety of Loading and Support Conditions. 1984, DTIC Document.

Ioannides, A. M., Peng, J., \& Swindler, J. R. J. (2006). ABAQUS model for PCC slab cracking. International Journal of Pavement Engineering, 7(4), 311-321.

Sargand, S., \& Breegle, D. (1998). Three-Dimensional Finite Element Software Development and Verification Case Study. In First National Symposium of 3D Finite Element for Pavement Analysis and Design.

Shoukry, S. (2000). Backcalculation of thermally deformed concrete pavements. Journal of the Transportation Research Board, 2000(1716), 64-72.

Shoukry, S. N., William, G. W., \& Riad, M. Y. (2003). Effect of Bonding Force on Stresses in Concrete Slabs. 2003, West Virginia Department of Transportation: West Virginia.

Shoukry, S. N., William, G., \& Riad, M. (2002). Characteristics of concrete contact stresses in doweled transverse joints. International Journal of Pavement Engineering, 3(2), 117-129.

Shoukry, S., Martinelli, D., \& Reigle, J. (1997). Universal pavement distress evaluator based on fuzzy sets. Journal of the Transportation Research Board, 1997(1592), 180-186. 
Shoukry, S., William, G., \& Srinivasan, S. (2002). Analysis of mid-slab transverse cracking in jointed concrete pavements. International Journal of Pavements, 1(3).

Siddharthan, R., Sebaaly, P. E., \& Zafir, Z. (1996). Dynamic response evaluation of inclined pavements with interface shear. International Journal of Heavy Vehicle Systems, 3(1-4), 382-398.

Tabatabaie, A., Barenberg, E., \& Smith, R. (1979). Longitudinal Joint Systems in Slip-Formed Rigid Pavements. Volume II. Analysis of Load Transfer Systems for Concrete Pavements. 1979, DTIC Document.

Wang, S. K., Sargious, M., \& Cheung, Y. K. (1972). Advanced analysis of rigid pavements. Journal of the Transportation Engineering Division, 98(1), 37-44.

Westergaard, H. (1927). Analysis of stresses in concrete pavements due to variations of temperature. in Highway Research Board Proceedings.

William, G. W., \& Shoukry, S. N. (2001). 3D finite element analysis of temperature-induced stresses in dowel jointed concrete pavements. International Journal of Geomechanics, 1(3), 291-307.

Zaghloul, S., et al. (1994). Dynamic analysis of FWD loading and pavement response using a three-dimensional dynamic finite-element program. Astm Special Technical Publication, 1198, 125-125.

Zokaei-Ashtiani, M. A., et al., (2013). Modeling of slab-foundation friction in jointed concrete pavements under nonlinear thermal gradient or traffic loads. Journal of the Transportation Research Board, 2013(2367), 123-131.

\section{Copyrights}

Copyright for this article is retained by the author(s), with first publication rights granted to the journal.

This is an open-access article distributed under the terms and conditions of the Creative Commons Attribution license (http://creativecommons.org/licenses/by/4.0/). 